\title{
IgG subclass distribution in serum and rectal mucosa of monozygotic twins with or without inflammatory bowel disease
}

\author{
L Helgeland, C Tysk, G Järnerot, K Kett, E Lindberg, D Danielsson, S N Andersen, \\ P Brandtzaeg
}

\begin{abstract}
Serum samples from 26 monozygotic twin pairs concordant or discordant with regard to inflammatory bowel disease, and rectal biopsies from 42 twins of the same subject group, were examined for IgG subclasses. They were all compared with normal controls. Almost al affected twins were in clinical remission. Paired immunofluorescence staining of the rectal mucosa showed that those with ulcerative colitis had a significantly higher $(p<0.01)$ proportion of IgG1 producing mucosal immunocytes than normal controls $(78.1 \% v$ $55.9 \%)$. Conversely, the IgG2 cell fraction was significantly reduced $(15.9 \% v 34.6 \%)$. Healthy twins from ulcerative colitis pairs tended to show a raised proportion of IgG1 cells and the IgG 2 cell fraction was significantly reduced $(p<0.05)$. In discordant ulcerative colitis twin pairs, no difference appeared in the cellular IgG subclass pattern between healthy and affected twins. Furthermore, the proportion of IgG1 in these healthy and diseased twins showed good correlation $(T=0.867)$. The results in rectal mucosa of twins with Crohn's disease were widely scattered and affected twins did not differ significantly from normal controls. Healthy twins, however, showed a marginally raised IgG1 cell proportion, but no correlation was seen between the IgG subclass fractions in discordant Crohn's disease twin pairs. The serum concentrations of IgG1 and IgG2 did not differ from normal controls in twins of either category. These results suggested that in ulcerative colitis, the aberrant mucosal production of IgG1 and IgG2 does not depend on active disease, but is apparently at least partially explained by a genetic impact. Conversely, the mucosal IgG subclass pattern in Crohn's disease appears to be determined mainly by exogeneous variables.
\end{abstract}

(Gut 1992; 33: 1358-1364)

Ulcerative colitis and Crohn's disease are chronic, remitting and relapsing mucosal disorders, collectively known as inflammatory bowel disease. The aetiology remains unknown, but much circumstantial evidence suggests that immunological mechanisms are involved in the pathogenesis. The established mucosal lesion in ulcerative colitis and Crohn's disease is dominated by terminally differentiated B cells appearing as plasma cells and blasts. In this immunocyte population there is a disproportionate expansion of the number of immuno- globulin G (IgG) producing immunocytes in affected areas. Immunohistochemical studies have shown that the IgG cell fraction is increased up to 30 times, depending on the severity of the lesion.' Furthermore, cultured mononuclear cells isolated from inflammatory bowel disease mucosa spontaneously secrete large amounts of IgG. ${ }^{2}$ These findings have led to the notion that IgG mediated immunopathological processes are of importance. ${ }^{3}$

The subclass composition of an IgG response is of biological significance because of the striking isotype related differences with regard to binding and activation of complement, promotion of phagocytosis, and mediation of antibody dependent cellular cytotoxicity. ${ }^{+5}$ Our laboratory has recently shown significant disparity between ulcerative colitis and Crohn's disease in terms of IgG subclass production in the mucosal lesion; the proportion of IgGl immunocytes was found to be higher in ulcerative colitis than in Crohn's colitis, while the reverse was true for the IgG2 cell fraction. ${ }^{6}$ These immunohistochemical observations were in good agreement with results obtained for IgG subclass synthesis revealed by spontaneous release from dispersed intestinal mononuclear cells. ${ }^{2}$ Similar disparity between the two disorders has also been reported for serum IgG subclass concentrations.?

The dissimilar IgG subclass distribution in ulcerative colitis and Crohn's disease might reflect different antigenic or mitogenic exposures in the gut. Another possibility is that the genetic regulation of the isotype response is different in the two populations of inflammatory bowel disease patients. Finally, it might be the result of an interplay between genetic and environmental factors. The influence of heredity is best studied in genetically identical twins. We have therefore examined the IgG subclass pattern in rectal immunocytes and in serum of monozygotic twins with or without inflammatory bowel disease. The study included pairs of twins both concordant and discordant with regard to ulcerative colitis or Crohn's disease. Furthermore, this material offered an opportunity to study the IgG subclass pattern in inactive stages of inflammatory bowel disease because the affected twins were in clinical remission. A histological normal control material was included for comparison.

\section{Methods}

TWINS

The study was approved by the Ethical Commit- 
tee, Örebro Medical Center Hospital, Örebro. By matching the Swedish twin registry at the Department of Environmental Hygiene, Karolinska Institute, Stockholm, with the central diagnosis register of hospital inpatients at the National Board of Health and Welfare, a population of monozygotic or dizygotic twins of the same sex has been identified. In our previous study, 34 monozygotic pairs with inflammatory bowel disease were found. ${ }^{8}$ Those who were younger than 75 years with both twins in each pair still alive were invited to participate in a clinical investigation. Two more recently diagnosed monozygotic pairs with inflammatory bowel disease were also invited. Fifty three of 66 total individuals agreed to participate. They constituted 14 pairs with Crohn's disease and 12 pairs with ulcerative colitis. The zygosity classification of the Swedish Twin Registry was used, which relies on questions on childhood resemblance. It has proved very accurate; in monozygotic twins a correct classification is obtained in $99 \%$ as verified by serological methods. ${ }^{9}$

The distribution of twins in concordant and discordant twin pairs, and the number of twins with an ileostomy, are shown in Table I. Among the 14 twins with ulcerative colitis, the mean age at diagnosis was 28.6 years (range 17-45); the actual study age was $49 \cdot 8$ years (range $24-74$ ). In the 19 twins with Crohn's disease, the mean age at diagnosis was 28.5 years (range $20-45$ ) and the actual study age 42.9 years (range $34-63$ ). All patients with ulcerative colitis were in clinical remission and had normal levels of haemoglobin, C-reactive protein, and serum orosomucoid. Six patients were treated with sulphasalazine and one healthy twin with prednisolone for chronic hepatitis, $5 \mathrm{mg}$ every second day. Two patients with Crohn's disease had mild diarrhoea and slightly increased C-reactive protein and orosomucoid concentrations. They were treated with sulphasalazine. Two patients had severe perianal disease preventing sigmoidoscopy. The others were inactive and no other therapy was given except vitamins or loperamide.

A thorough interview revealed no symptoms suggestive of inflammatory bowel disease in the healthy twins. The healthy twins have remained healthy for 21.4 years (range 8-40) after the

TABLE I Numberical distribution of twins with ulcerative colitis and Crohn's disease in healthy and diseased twins. In concordant pairs, both individuals are categorised as 'diseased'; in discordant pairs, one is grouped under 'diseased' and the other under 'healthy'

\begin{tabular}{|c|c|c|c|}
\hline \multicolumn{2}{|c|}{ Ulcerative colitis } & \multicolumn{2}{|c|}{ Crohn's disease } \\
\hline Diseased & Healthy & Diseased & Healthy \\
\hline $\begin{array}{l}1 \\
2 \\
3^{\star} \\
4 \\
5 \\
6,6 \\
7^{\star} \\
8 \\
9,9 \\
10^{\star} \\
11 \\
12^{\star}\end{array}$ & $\begin{array}{r}1 \\
2 \\
3 \\
4 \\
5 \\
7 \\
7 \\
\\
10 \\
11 \\
12\end{array}$ & $\begin{array}{l}14 \\
15 \\
16^{\star} \\
17,17 \\
18^{\star} \\
19^{\star} \\
20 \\
21,21 \\
22 \\
23 \\
24 \\
25,25 \\
26+, 26+ \\
27,27\end{array}$ & $\begin{array}{l}14 \\
15 \\
16 \\
18 \\
19 \\
20 \\
22 \\
23 \\
24\end{array}$ \\
\hline
\end{tabular}

^Proctocolectomy; †Perianal Crohn's disease and no sigmoidoscopy performed. diagnosis of the matching twins who had ulcerative colitis and for 14.9 years (range 7-31) in the twins discordant with those who had Crohn's disease.

Venous blood was obtained from all twins. After centrifugation, aliquots of serum were frozen at $-70^{\circ} \mathrm{C}$ until analysis. Furthermore, rectal biopsy specimens were obtained from each twin in whom sigmoidoscopy could be carried out. In the ulcerative colitis group, 10 of the 14 diseased twins had a rectum available for biopsy. Rectal biopsy specimens were collected from all 10 healthy ulcerative colitis twins. In 14 of the 19 diseased Crohn's disease twins, sigmoidoscopy could be performed. The biopsy from one of the nine healthy Crohn's disease twins turned out to be inadequate for immunohistochemical evaluation. Because some twin pairs were concordant with regard to inflammatory bowel disease, and rectal biopsy specimens were not available in some diseased twins, biopsy specimens from six healthy twins were unpaired. They were, however, included in the analysis because, being monozygotic, these twins are genetically identical with those who ultimately developed inflammatory bowel disease.

\section{NORMAL CONTROLS}

Normal colonic mucosal specimens were obtained from six men and four women with a mean age of 58.2 years (range $44-70$ ). This material was collected from macroscopically uninvolved areas of ascending or transverse colon (five), or descending or sigmoid colon (five); the specimens had been surgically resected as a result of colonic carcinoma (eight), polyposis (one), or diverticulitis (one). Histological evaluation showed no signs of inflammation or dysplasia.

In the study of serum immunoglobulins and serum IgG subclasses, each twin pair had two healthy controls matched for sex and age.

\section{IMMUNOHISTOCHEMISTRY}

Mucosal tissue specimens were extracted in cold phosphate buffered isotonic saline $(\mathrm{pH} \mathrm{7 \cdot 4)}$ for 48 hours before ethanol fixation and paraffin embedding. ${ }^{10}$ Serial sections were cut at $6 \mu \mathrm{m}$ from each tissue block. One section was stained with haematoxylin and eosin for histological evaluation.

At least four serial tissue sections, depending on the density of IgG producing cells, were subjected to paired immunofluorescence staining for one of the four IgG subclasses and for total IgG. Each dewaxed section was first incubated with murine monoclonal antibody (ascites 1:800) to either IgG1 (HP 6070, clone 2C7), IgG2 (HP 6009, clone GOM2), IgG3 (HP 6048 , clone CB1-AH7) or IgG4 (HP 6011, clone RJ4) and subsequently with a mix of fluorescein isothiocyanate labelled rabbit antimouse IgG and rhodamine B sulphonyl chloride labelled antihuman IgG. The sources of monoclonal antibodies, ${ }^{11}$ the characteristics of the fluorochrome conjugates, ${ }^{12}$ and other details of this two colour staining procedure ${ }^{6}$ have been reported previously. 


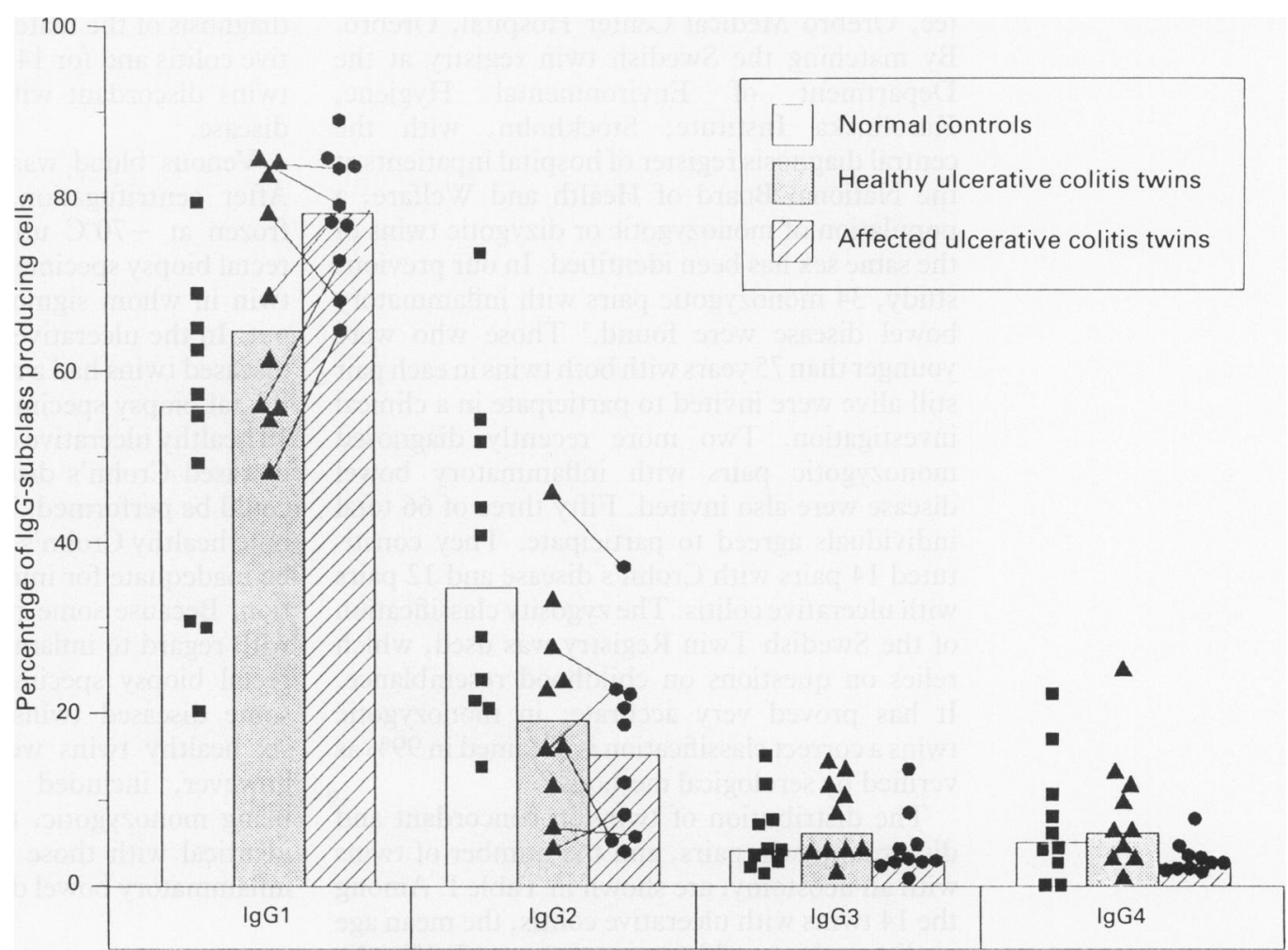

Figure 1: Scatter diagram of IgG subclass proportions of mucosal IgG producing cells in twin pairs with ulcerative colitis and controls. Matched twins of discordant pairs are connected by lines for IgGI and IgG2. Columns indicate medians.

MICROSCOPY AND CELL COUNTING

The sections were evaluated in a Leitz Orthoplan microscope equipped with a Ploem type vertical illuminator with interference filters for selective observation of fluorescein (green) or rhodamine (red) emission. Immunocytes with distinct cytoplasmic fluorescence were counted using an $\times 25$ immersion objective and an $\times 10$ ocular. The enumerations were performed by the same investigator ( $\mathrm{LH})$ throughout the study. The intraobserver and interobserver reproducibility showed good correlation and no systematic error was noted for this enumeration method in previous studies. ${ }^{613}$

Although section area and orientation differed among the tissue blocks, the epithelium and lamina propria were easily identified. Up to five sections were examined for each subclass because of the scarcity of IgG-producing cells in some specimens. The median number of 'red' cells (total IgG population) evaluated for concomitant 'green' subclass staining per specimen was 223 in controls (range 121-878), 1194 in the ulcerative colitis group (range 246-1964), and 1188 in the Crohn's disease group (range 3161952). The proportion of each subclass was calculated in relation to the total number of IgG producing cells present in the evaluated area of the same section. The sum of the four subclass proportions in serial sections from each tissue block was usually around $100 \%$ (range $94 \%$ $112 \%)$. Variations could probably be ascribed mainly to minor topographical differences in the subclass distribution. The sum of the subclass medians was for controls $\mathbf{9 9 . 7 \%}$; for the ulcerative colitis group $101 \cdot 1 \%$; and for the Crohn's disease group $96.4 \%$. These figures attested to the high reproducibility of this counting method.

\section{HISTOPATHOLOGICAL EVALUATION}

Rectal tissue sections stained with haematoxylin and eosin from all the monozygotic twins were examined by an experienced pathologist with regard to inflammatory changes. The following variables were evaluated: crypt branching, atrophy, thickening of the epithelial basement membrane and muscularis mucosae, fibrosis and density of inflammatory cell infiltrate.

\section{DETERMINATION OF IMMUNOGLOBULIN \\ CONCENTRATIONS IN SERUM}

Total serum IgG, IgA, and $\operatorname{Ig} M$ were determined by radial immunodiffusion according to Mancini et $a l^{14}$ Immunoplates with polyclonal antibodies were purchased from Behringwerke $\mathrm{A} / \mathrm{S}$, Germany, and the recommendations by the manufacturer were followed. The determination of IgG subclasses $1,2,3$, and 4 were made by radial immunodiffusion with the use of monoclonal antibodies purchased from Seward Laboratories, UK. The manufacturer's recommendations were followed. All determinations were done twice with variations between the tests of less than $\pm 10 \%$.

\section{STATISTICAL ANALYSES}

The twins were divided into four test groups: twins with ulcerative colitis, healthy twins from discordant twin pairs of whom the affected ones had ulcerative colitis, twins with Crohn's disease, and healthy twins from discordant twin pairs of whom the affected ones had Crohn's disease.

Differences in median cellular proportions of the four IgG subclasses among these groups and in relation to the controls were determined by Wilcoxon's two tailed test for unpaired samples. 
Figure 2: Scatter diagram of IgG subclass proportions of mucosal IgG producing cells in twin pairs with Crohn's disease and controls.

Matched twins of discordant pairs are connected by lines for IgGI and IgG2.

Columns indicate medians.

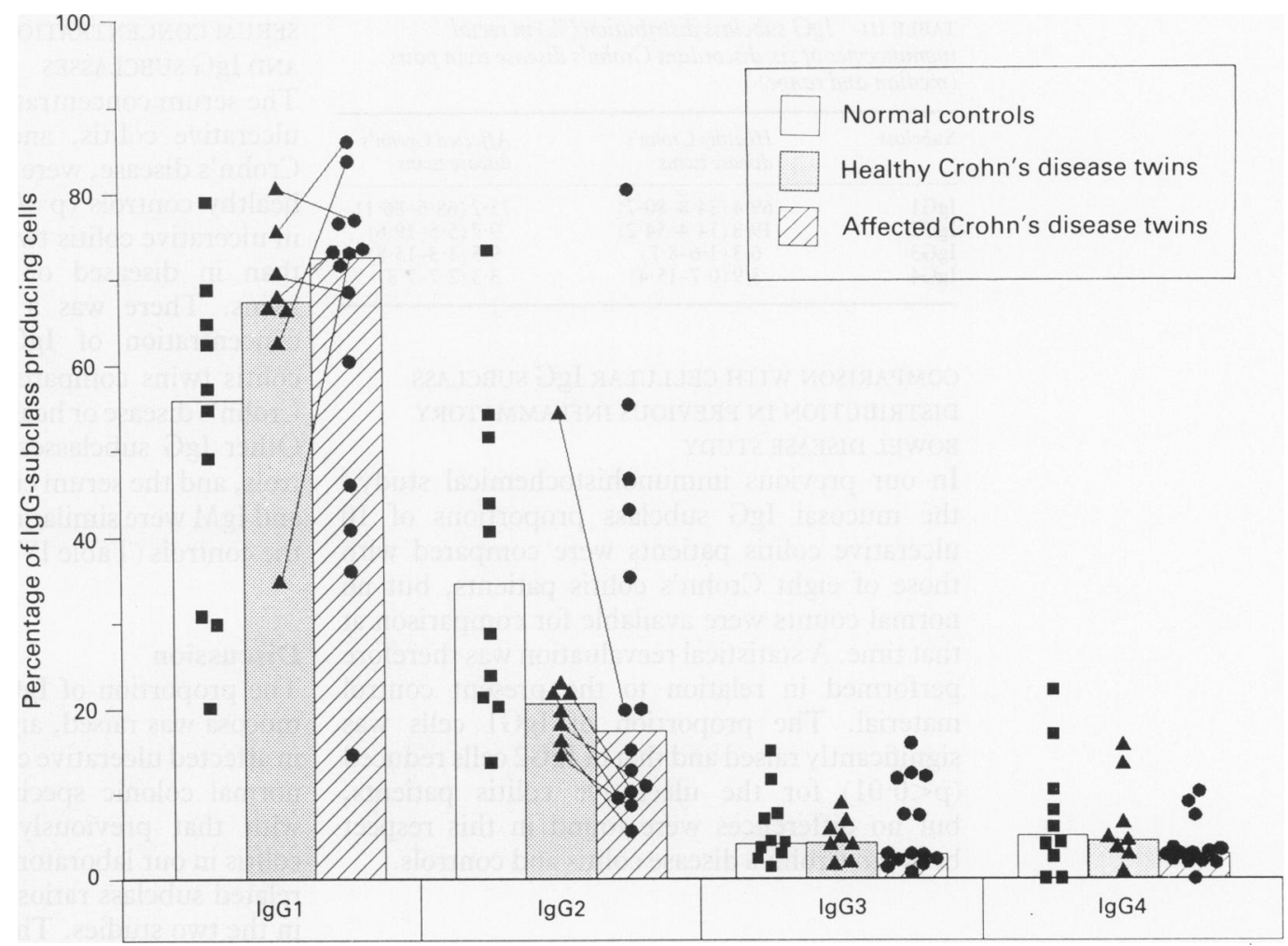

Similar comparisons were performed between the inflammatory bowel disease material previously analysed by immunohistochemistry in our laboratory ${ }^{6}$ and the present control material. In six discordant twin pairs with ulcerative colitis, and six discordant twin pairs with Crohn's disease, Wilcoxon's two tailed test for paired samples was used. Relations between healthy and affected twins with regard to IgG1 and IgG2 cell proportions in these pairs were estimated by the Kendall rank correlation test.

Serum concentrations of immunoglobulins and IgG subclasses were presented as mean (SD). Differences between means were tested with Student's $t$ test and $\mathrm{p}<0.05$ was considered statistically significant.

\section{Results}

SUBCLASS DISTRIBUTION OF IgG PRODUCING CELLS IN INFLAMMATORY BOWEL DISEASE TWINS AND NORMAL COLONIC MUCOSA

In general, there were large variations in cellular subclass distribution among individuals, in the inflammatory bowel disease twins and normal controls. The results for ulcerative colitis twins are compared with controls in Figure 1. The median proportion of IgG1 immunocytes in twins with ulcerative colitis $(78 \cdot 1 \%)$ was significantly higher $(\mathrm{p}<0.01)$ than in controls $(55 \cdot 9 \%)$. Conversely, the proportion of IgG2 cells was lower $(p<0.01)$ in twins with ulcerative colitis $(15.9 \%)$ than in controls $(34.6 \%)$. In discordant twin pairs of whom the diseased twin had ulcerative colitis, the healthy ones tended to have a raised proportion of IgGl cells $(64 \cdot 6 \%)$, and the IgG 2 cell fraction was significantly $(p=0.05)$ reduced $(19 \cdot 1 \%)$ compared with controls. In contrast, affected Crohn's disease twins showed a wide scatter of results and did not differ significantly from controls in IgG1 and IgG2 proportions (Fig 2). Healthy twins from pairs with Crohn's disease nevertheless showed a marginally raised IgG1 percentage $(67 \cdot 4 \% ; p=$ 0.05 ). A trend towards reduced proportions of IgG3 in affected ulcerative colitis twins, and IgG4 in affected Crohn's disease twins was also noted, but this was not statistically significant.

Median proportions of IgG 1 and IgG2 cells did not differ between healthy and diseased twins with either ulcerative colitis or Crohn's disease. The influence of the presence or absence of disease, however, might have been masked by the large individual variations in subclass proportions. The monozygotic twin material consisted of both concordant and discordant twin pairs, and some unpaired healthy twins. Discordant twin pairs with either ulcerative colitis or Crohn's disease, in whom data were available for both twins, were therefore analysed further for both inflammatory bowel disease categories; no significant differences in subclass proportions appeared between healthy and diseased twins (Tables II and III). Furthermore, the proportions of IgGl cells in healthy and diseased ulcerative colitis twins were well correlated (Fig 3a). Conversely, no such correlation was found in the discordant Crohn's disease twin pairs (Fig 3b). The other IgG subclasses were not correlated at the cellular level in either ulcerative colitis or Crohn's disease twins.

TABLE II IgG subclass distribution (\%) in rectal immunocytes of six discordant ulcerative colitis twin pairs (median and range)

\begin{tabular}{lcc}
\hline Subclass & Healthy UC twins & Affected UC twins \\
\hline IgG1 & $73 \cdot 0(47 \cdot 8-84 \cdot 1)$ & $74 \cdot 8(64 \cdot 4-83 \cdot 3)$ \\
IgG2 & $15 \cdot 7(4 \cdot 1-45 \cdot 4)$ & $16 \cdot 8(5 \cdot 8-36 \cdot 9)$ \\
IgG3 & $8 \cdot 6(1 \cdot 3-13 \cdot 1)$ & $2 \cdot 9(2 \cdot 7-13 \cdot 3)$ \\
IgG4 & $6 \cdot 1(2 \cdot 9-12 \cdot 8)$ & $2 \cdot 5(1 \cdot 5-7 \cdot 6)$ \\
\hline
\end{tabular}

$\mathrm{UC}=$ ulcerative colitis 
TABLE III IgG subclass distribution (\%) in rectal immunocytes of six discordant Crohn's disease twin pairs (median and range)

\begin{tabular}{lll}
\hline Subclass & $\begin{array}{l}\text { Healthy Crohn's } \\
\text { disease twins }\end{array}$ & $\begin{array}{l}\text { Affected Crohn's } \\
\text { disease twins }\end{array}$ \\
\hline IgG1 & $69 \cdot 4(34 \cdot 8-80 \cdot 7)$ & $75 \cdot 2(68 \cdot 6-86 \cdot 1)$ \\
IgG2 & $19 \cdot 8(14 \cdot 4-54 \cdot 2)$ & $9 \cdot 7(5 \cdot 5-19 \cdot 6)$ \\
IgG3 & $6 \cdot 3(1 \cdot 6-8 \cdot 7)$ & $9 \cdot 5(1 \cdot 3-15 \cdot 8)$ \\
IgG4 & $3 \cdot 9(0 \cdot 7-15 \cdot 4)$ & $3 \cdot 3(2 \cdot 7-7 \cdot 3)$ \\
\hline
\end{tabular}

COMPARISON WITH CELLULAR IgG SUBCLASS DISTRIBUTION IN PREVIOUS INFLAMMATORY BOWEL DISEASE STUDY

In our previous immunohistochemical study, the mucosal IgG subclass proportions of 10 ulcerative colitis patients were compared with those of eight Crohn's colitis patients, but no normal counts were available for comparison at that time. A statistical reevaluation was therefore performed in relation to the present control material. The proportion of IgG1 cells was significantly raised and that of IgG2 cells reduced $(\mathrm{p}<0.01)$ for the ulcerative colitis patients, but no differences were found in this respect between Crohn's disease colitis and controls.

HISTOPATHOLOGICAL EVALUATION

Microscopic examination in haematoxylin and eosin stained sections revealed only minor alterations except in one concordant and clinical slightly affected Crohn's disease twin pair in whom overt signs of inflammation were present in both twins. Their mucosal IgG subclass pattern, however, did not differ consistently from the other Crohn's disease twins.

TABLE IV Serum concentrations (mean (SD)) of IgG, IgA, IgM and the subclasses IgGI through IgG4 in twins with ulcerative colitis (UC), their healthy twin siblings $(H-U C)$, twins with Crohn's disease $(C D)$, their healthy twin siblings $(H-C D)$ and healthy controls

\begin{tabular}{|c|c|c|c|c|c|}
\hline & $\begin{array}{l}U C \\
(n=14)\end{array}$ & $\begin{array}{l}H-U C \\
(n=10)\end{array}$ & $\begin{array}{l}C D \\
(n=19)\end{array}$ & $\begin{array}{l}H-C D \\
(n=9)\end{array}$ & $\begin{array}{l}\text { Controls } \\
(n=54)\end{array}$ \\
\hline $\begin{array}{l}\text { IgG } \\
\text { IgA } \\
\text { IgM } \\
\text { IgG1 } \\
\text { IgG2 } \\
\text { IgG3 } \\
\text { IgG4 }\end{array}$ & $\begin{array}{c}14.41(2.36) \\
3.26(0.76) \\
2.04(1.25) \\
6.61(1.89) \\
5.38(1.51) \\
0.34(0.30) \star \\
0.41(0.45)\end{array}$ & $\begin{array}{r}13.78(2.43) \\
3.11(1.11) \\
2.07(0.91) \\
6.29(2.02) \\
5.46(1.01) \\
0.45(0.25) \\
0.44(0.41)\end{array}$ & $\begin{array}{c}13.59(2.42) \\
3.87(1.86) \\
1.96(1.11) \\
6.35(1.75) \\
4.41(1.70) \\
0.72(0.38) \\
0.30(0.24)^{\star}\end{array}$ & $\begin{array}{r}14.87(1.64) \\
2.84(0.67) \\
1.93(0.66) \\
6.30(1.32) \\
5.08(1.11) \\
0.73(0.40) \\
0.39(0.32)\end{array}$ & $\begin{array}{c}14.26(3.31) \\
3.14(1.28) \\
2.07(0.99) \\
6.37(2.42) \\
5.18(2.50) \\
0.62(0.43) \\
0.48(0.30)\end{array}$ \\
\hline
\end{tabular}

${ }^{\star} \mathrm{p}<0.05$ vs controls.
SERUM CONCENTRATIONS OF IMMUNOGLOBULINS AND IgG SUBCLASSES

The serum concentrations of IgG3 in twins with ulcerative colitis, and of IgG4 in twins with Crohn's disease, were significantly lower than in healthy controls $(p=0 \cdot 02)$. Furthermore, IgG3 in ulcerative colitis twins was significantly lower than in diseased or healthy Crohn's disease twins. There was a tendency towards lower concentration of $\operatorname{IgG} 3$ in healthy ulcerative colitis twins compared with both controls and Crohn's disease or healthy Crohn's disease twins. Other IgG subclasses did not differ from controls, and the serum concentrations of IgG, IgA, and $\operatorname{Ig} M$ were similar in the four twin groups and the controls (Table IV).

\section{Discussion}

The proportion of IgGl immunocytes in rectal mucosa was raised, and that of IgG2 decreased, in affected ulcerative colitis twins compared with normal colonic specimens. This result agrees with that previously obtained for ulcerative colitis in our laboratory, ${ }^{6}$ and the median disease related subclass ratios were in fact quite similar in the two studies. These findings are further in keeping with cultivation studies of mononuclear cells from inflamed ulcerative colitis mucosa which showed preferential spontaneous secretion IgGl compared with control cells. ${ }^{2}$

Theoretically, the IgG subclass distribution could be different in superficial as opposed to basal lamina propria. Thus, the variable orientation and size of individual tissue samples might have affected our results. A large number of cells (mean $>1000$ cells/specimen) was therefore evaluated to obtain representative results from all parts of mucosa, usually including five sections for each IgG subclass. The fact that the subclass distribution in the diseased twins was almost identical to previous results in inflammatory bowel disease patients, ${ }^{6}$ attests to the reliability of our counting method.

The affected ulcerative colitis twins were in clinical remission at the time of biopsy, and histological evaluation showed no signs of mucosal inflammation. The actual number of IgG producing cells per mucosal length unit could not be quantified because of problems with

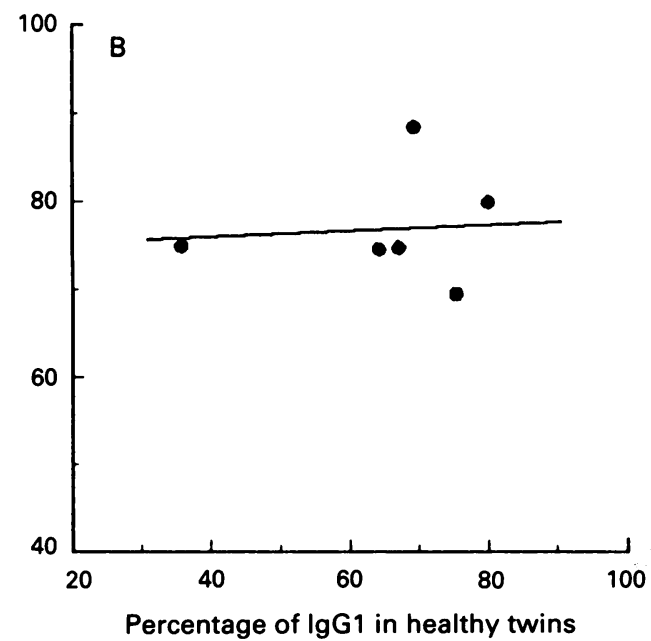

Figure 3: Relation of rectal cellular percentages between healthy and affected twins in six discordant twin pairs with $(A)$ ulcerative colitis $(T=0.8667)$ and $(B)$ Crohn's disease.

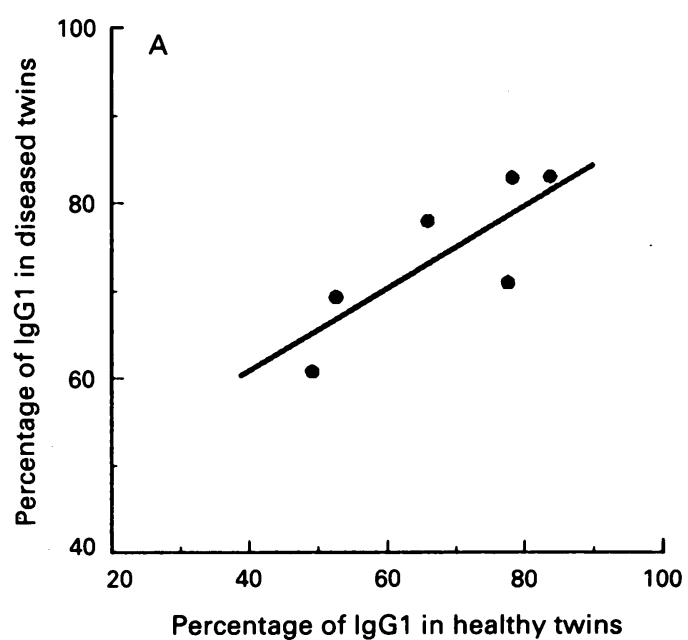


the sample orientation. By performing blind semiquantitive IgG cell density scoring, however, we did not notice any difference between affected and healthy twins (data not shown). In the light of previous reports on an association between the number of mucosal IgG producing cells and inflammatory activity, ${ }^{15} 16$ our study suggests that the cellular IgG subclass distribution in ulcerative colitis does not depend on the magnitude of the local IgG response. The raised IgGl proportion appears to be disease specific instead and not a reflection of unspecific inflammatory changes. The tendency of the healthy ulcerative colitis twins to show a raised IgG1 proportion, along with a significantly reduced IgG2 proportion, supports this notion.

The total IgG production in the mucosa was probably not increased in the diseased or healthy ulcerative colitis twins; this could explain the fact that their serum concentrations of IgGl and IgG2 did not differ from controls, which is in contrast with previous observations in active disease. ${ }^{7}$ There was a tendency towards a lower proportion of IgG3 cells in ulcerative colitis mucosa, along with a significantly decreased serum concentration of IgG3 in ulcerative colitis twins compared with controls. This has not been found in previous studies. Further investigations are needed to determine if also this aberration is specific for ulcerative colitis.

It has been suggested that Crohn's disease gives rise to a relatively enhanced production of IgG2 compared with IgG1, ${ }^{267}$ but this did not hold true when we compared immunohistochemical data from our present and previous ${ }^{6}$ study with controls. On the contrary, there was a tendency towards a reduced proportion of IgG2 in healthy and affected Crohn's disease twins as well as in the previously analysed Crohn's disease colitis patients with moderate or severe mucosal inflammation. ${ }^{6}$ It rather appeared to be a slight but inconsistent preference for mucosal IgG1 production also in Crohn's disease.

There is no doubt that genetic factors are involved in inflammatory bowel disease, although the influence of heredity might be different in the two diseases. ${ }^{817}$ The genetic impact on the mucosal IgG subclass response could also be different in the two diseases. In ulcerative colitis, we found that the cellular proportions of IgG1 and IgG2 in healthy twins were somewhere between controls and affected twins; but when comparing healthy and affected twins, no statistically significant differences appeared. In view of the large individual variations, and also the fact that some twins included were unpaired, the influence of disease might have been more or less masked. We therefore separately analysed six discordant twin pairs, and found no significant differences between healthy and affected twins. Therefore, the factor(s) responsible for the enhanced IgG1 response in ulcerative colitis appeared to be present also in healthy twins. This notion was further supported by the strong correlation revealed for cellular IgGl proportions in healthy and affected ulcerative colitis twins.

A possible interpretation of these findings is that genetic mechanisms are involved in the regulation of the IgG subclass response. The switch region associated with the $\mathrm{CH} \gamma \mathrm{l}$ gene may be more efficient in the ulcerative colitis population. Certain IgG heavy chain markers are associated with the serum concentrations of IgG subclasses. For example, individuals without the G2 marker $n$ have lower serum concentration of IgG2 than carriers of the $\mathrm{G} 2 \mathrm{~m}(n) .{ }^{18}$ Another mechanism may be that certain $\mathrm{VH}$ genes, directed against antigens which are important to the IgG response in ulcerative colitis, preferentially associate with particular $\mathrm{CH}$ genes in the ulcerative colitis population. Several studies have disclosed relations between IgG markers and IgG subclass serum concentrations against particular antigens. ${ }^{1920}$ Interestingly, a recent German study showed an association between ulcerative colitis and $\mathrm{Gm} 1,-2,10 .^{21}$ Similar genetic mechanisms may be involved in autoimmune diseases in general. Several studies have disclosed increased serum levels of IgG1 in a number of autoimmune diseases. ${ }^{72-24}$

The similarity in IgG subclass proportions between healthy and affected ulcerative colitis twins might also reflect stimulation by a particular antigen(s). Numerous studies have shown IgG antibodies in serum of inflammatory bowel disease patients directed towards cow's milk proteins, bacteria, cytoskeleton and different epithelial cell associated antigens. ${ }^{25-30}$ The latter antibodies have also been detected in serum of non-affected family members of inflammatory bowel disease patients. ${ }^{31}$ A $40-\mathrm{kD}$ colon specific epithelial membrane glycoprotein bound to IgG have been isolated from ulcerative colitis lesions. ${ }^{32}$ Such tissue bound IgG might predominantly be IgGl because this subclass has recently been shown together with terminal complement complex on the luminal face of the epithelium in ulcerative colitis. ${ }^{33}$

In one study in the United States, certain IgGl and IgG3 heavy chain markers were found to be associated with Crohn's disease. ${ }^{34}$ Others have not been able to confirm this association. ${ }^{35} \mathrm{We}$ found no differences in the median cellular proportions of IgG subclasses between healthy and affected Crohn's disease twins and in the separately analysed discordant twin pairs. Also in contrast with the ulcerative colitis twins, there was no IgGl cell correlation between healthy and affected paired twins, and the range in IgG subclass proportions was much larger. Even concordant Crohn's disease twins affected by the disease usually showed very dissimilar subclass ratios. This suggested that the mucosal IgG subclass response in Crohn's disease is mainly determined by exogeneous variables. The data might reflect that many different antigens affect the mucosal immune response pattern in both affected and non-affected Crohn's disease twins. Conversely, our data strongly suggested a substantial genetic impact on the preferential local IgGl response in ulcerative colitis.

1 Baklien K, Brandtzaeg P. Comparative mapping of the local distribution of immunoglobulin-containing cells in ulceraImmunol 1975; 22: 197-209.

2 Scott MG, Nahm MH, Macke K, Nash GS, Bertovich MJ, MacDermott RP. Spontaneous secretion of IgG subclasses by intestinal mononuclear cells: differences between ulcerative colitis, Crohn's disease, and controls. Clin Exp Immuno 1986; 66: 209-15. 
3 Brandtzaeg P, Kett K, Halstensen TS, Helgeland L. Pathogenesis of ulcerative colitis and Crohn's disease: Humoral immune mechanisms. Eur f Gastrointerol Hepatol 1990; 2: 256-65.

4 Garred P, Michaelsen TE, Aase A. The IgG subclass pattern of complement activation depends on epitope density and
complement concentration. Scand f Immunol 1989; 30: 37982 .

5 Kumpel BM, Wiener E, Urbaniak SJ, Bradley BA. Human monoclonal anti-D antibodies. II: The relationship between $\mathrm{IgG}$ subclass, $\mathrm{Gm}$ allotype and $\mathrm{Fc}$ mediated function. $\mathrm{Br} \mathcal{F}$ Haematol 1989; 71: 415-20.

6 Kett K, Rognum TO, Brandtzaeg P. Mucosal subclass distribution of immunoglobulin G-producing cells is different in ulcerative colitis and Crohn's disease of the colon. Gastroenterology 1987; 93: 919-24.

7 MacDermott RP, Nash GS, Auer IO, Shlien R, Lewis BS, Madassery $\mathrm{J}$, et al. Alterations in serum immunoglobulin $\mathrm{G}$ subclasses in patients with ulcerative colitis and Crohn's disease. Gastroenterology 1989; 96: 764-8.

8 Tysk C, Lindberg E, Järnerot G, Flodérus-Myrhed B Ulcerative colitis and Crohn's disease in an unselected Ulcerative colitis and Crohn's disease in an unselected
population of monozygotic and dizygotic twins. A study of population of monozygotic and dizygotic twins. A study of $990-6$

9 Cederlöf R, Friberg L, Jonsson E, Kaij L. Studies on similarity diagnosis in twins with the aid of questionnaires. Acta Genet 1961; 11 : 338-62.

10 Brandtzaeg P. Mucosal and glandular distribution of immunoglobulin components. Immunohistochemistry with a cold ethanol-fixation technique. Immunology 1974; 26: 1104-14.

11 Jefferies R, Reimer CB, Skavril F, et al. Evaluation of monoclonal antibodies having specificity for human IgG subclasses: results of an IUIS/WHO collaborative study. Immunol Lett 1985; 10: 223-52.

12 Brandtzaeg P, Kett K, Rognum TO, Søderstrøm R Bjørkander J, Søderstrøm T, et al. Distribution of mucosal IgA and IgG subclass-producing immunocytes and alterations in various disorders. Monogr Allergy 1986; 20: 179-94.

13 Nilssen DE, Søderstrøm R, Brantzaeg P, Kett K, Helgeland $\mathrm{L}$, Karlsson $\mathrm{G}$, et al. Isotype distribution of mucosal IgGproducing cells in patients with various IgG-subclas deficiencies. Clin Exp Immunol 1991; 83: 17-24.

14 Mancini G, Carbonara AO, Heremans JF. Immunochemical quantitation of antigens by single radial immunodiffusion. Immunochemistry 1965; 2: 235-54.

15 Scott BB, Goodall A, Stephenson P, Jenkins D. Rectal mucosal plasma cells in inflammatory bowel disease. Gut 1983; 24: 519-24.

16 Keren DF, Appelman HD, Dobbins WO, Wells JJ, Whisenant B, Foley J, et al. Correlation of histopathologic evidence of disease activity with the presence of immunoglobulin-containing cells in the colons of patients with inflammatory bowel disease. Hum Pathol 1984; 15: 757-63.

17 Peña AS, Weterman IT, Lamers CBHW. Predisposing markers and regulating genes in inflammatory bowe disease. In: Järnerot G, ed. Inflammatory bowel disease. Raven Press, 1987: 9-19.

18 Rautonen N, Sarvas H, Mäkelä O. One allele [G2m(n)] of the human IgG2 locus is more productive than the other. $E$ ur $\mathcal{F}$ Immunol 1989; 19: 817-22.
19 Morell A, Vassalli G, deLange GG, Skvaril F, Ambrosino DM, Sieber GR. Ig allotype-linked regulation of class and subclass composition of natural antibodies to group A streptococcal carbohydrate. F Immunol 1989; 142: 2495500 .

20 Sarvas H, Rautonen N, Sipinen S, Mäkelä O. IgG subclasses of pneumococcal antibodies-effect of allotype $\mathrm{G} 2 \mathrm{~m}(\mathrm{n})$. Scand $\mathcal{F}$ Immunol 1989; 29: 229-37.

21 Purrmann J, Bertrams J, Knapp M, Cleveland S, Gemsa R, Hengels $\mathrm{KJ}$, et al. Investigation of genetic markers in patients with Crohn's disease and ulcerative colitis. Z Gastroenterol 1989; 27: 366-9.

22 Shakib F, Stanworth DR. Human IgG subclasses in health and disease. Ric Clin Lab 1980; 10: 561-80.

23 Heiner DC. Significance of immunoglobulin G subclasses. Am 7 Med 1984; 76: 1-6.

24 Oxelius VA. Immunoglobulin G (IgG) subclasses and human disease. Am F Med 1984; 76: 7-18.

25 Lerner A, Rossi TM, Park B, Albini B, Lebenthal E. Serum antibodies to cow's milk proteins in pediatric inflammatory bowel disease Acta Paediatr $S$ cand 19

26 Paganelli R, Pallone F, Montano S, Le Moli S, Matricardi PM, Fais $S$, et al. Isotypic analysis of antibody response to a food antigen in inflammatory bowel disease. Int Archs Allergy Appl Immunol 1985; 78: 81-5.

27 Bull K, Matthews N, Rhodes J. Antibody response to anaerobic coccoid rods in Crohn's disease. 7 Clin Pathol 1986; 39: 1130-4

28 Skogh T, Bodemar G, Kihlström E, Ljunghusen O. Antibrush border antibodies (ABBA) in sera from patients with ulcerative protocolitis and in sera with antibodies against Yersinia enterocolitica O:3. F Clin Lab Immunol 1986; 19: 117-8.

29 Zauli D, Crespi C, Dall'Amore. P, Bianchi FB, Pisi P. Antibodies to the cytoskeleton components and other auto-
antibodies in inflammatory bowel disease. Digestion 1985; antibodies

30 Hibi T, Aiso $M$, Ishikawa $M$, Watanabe $M$, Yoshida $T$, Kobayashi $\mathrm{K}$, et al. Circulating antibodies to the surface antigens on colon epithelial cells in ulcerative colitis. Clin Exp Immunol 1983; 54: 163-8.

31 Fiocchi C, Roche JK, Michener WM. High prevalence of antibodies to intestinal epithelial antigens in patients with inflammatory bowel disease and their relatives. Ann Interm Med 1989; 110: 786-94.

32 Takahashi F, Das KM. Isolation and characterization of a colonic autoantigen specifically recognized by colon tissuebound immunoblogulin $\mathrm{G}$ from idiopathic ulcerative colitis. f Clin Invest 1985; 76: 311-8.

33 Halstensen TS, Mollnes TE, Garred P, Fausa O, Brandtzaeg P. Epithelial deposition of immunoglobulin $\mathrm{Gl}$ and activated complement ( $\mathrm{C} 3 \mathrm{~b}$ and terminal complement complex) in ulcerative colitis. Gastroenterology 1990; 98: 1264-71.

34 Kagnoff MF, Brown RJ, Schanfield MS. Association between Crohn's disease and immunoglobulin heavy chain $(\mathrm{Gm})$ allotypes. Gastroenterology 1983; 85: 1044-7.

35 Leigh Field L, Boyd N, Bowen TJ, Kelly JK, Sutherland LR. Genetic markers and inflammatory bowel disease: Immunoglobulin allotypes $(\mathrm{Gm}, \mathrm{Km})$ and protease inhibitor. $A m \mathcal{F}$ Gastroenterol 1989; 84: 753-5. 